\title{
Concepções dos familiares de crianças que utilizam o serviço de estimulação
}

\author{
precoce
}

\section{Conceptions of family members of children who use the early intervention}

\author{
Julia Lopes*, Thays Votto**, Daniela Delias***, Carla de Felippe**** \\ Universidade Federal do Rio Grande - FURG, Brasil
}

\begin{abstract}
Resumo
O objetivo deste estudo foi conhecer as concepções dos familiares sobre a descoberta da deficiência e os benefícios da estimulação precoce a partir do relato de três famílias de crianças que utilizam o serviço em uma instituição de um município do Sul do Brasil. Trata-se de um estudo de casos múltiplos de natureza qualitativa. A coleta de dados foi realizada por meio de entrevistas semiestruturadas, analisadas por meio da Análise de Conteúdo. Os resultados indicam que os sentimentos em relação à descoberta da deficiência evoluem da frustração à aceitação e que os familiares reconhecem os benefícios do serviço.

Palavras-chave: estimulação precoce, educação especial, desenvolvimento infantil
\end{abstract}

\begin{abstract}
The aim of this study was to know the conceptions of the family members about the discovery of disability and the benefits of early intervention from the report of three families of children who use the service in a municipal institution in the south of Brazil. It is a study of multiple cases of qualitative nature. The data production tool was conducted through semi-structured interviews, analyzed by Content Analysis. The results indicate that feelings about the discovery of disability evolve from frustration to acceptance and that family members recognize the benefits of the service.

Keywords: early intervention, special education, childhood development
\end{abstract}

\section{Introdução}

O termo estimulação precoce é derivado da expressão inglesa early intervention. No Brasil, o termo é comumente utilizado em práticas de atendimento especializado a crianças com necessidades específicas. Indagações a respeito da utilização da expressão têm resultado no emprego de outras terminologias, tais como estimulação essencial, educação precoce, intervenção precoce e intervenção essencial. (Ministério da Educação [MEC], 1995a). Neste estudo, optou-se por utilizar o termo estimulação precoce $(\mathrm{EP})$ concernente à modalidade de atividades que integra ações de múltiplos setores, como o educacional, de saúde e assistência social, para impulsionar o desenvolvimento da criança em seus três primeiros anos de vida em diversas áreas funcionais visando mudanças significativas em seu processo de desenvolvimento.
A família, grupo social primário (Pichon-Rivière, 1998), passa por diferentes modificações de acordo com as demandas sociais, seja em suas configurações ou crenças e atitudes relacionadas à entrada de novos membros. Entretanto, tende a organizar-se em prol de dois objetivos, a saber, um interno, referente à proteção psicossocial de seus membros, e um externo, que diz respeito à acomodação em uma cultura e a transmissão desta. (Minuchin, 1982). Neste contexto, quando a família descobre um novo membro com alguma deficiência, sua dinâmica e sentimentos influenciarão na integração social deste último sob dois ângulos opostos: a facilitação ou o impedimento à integração da pessoa com deficiência, tanto na família quanto na comunidade. (Glat, 1996). Tais sentimentos, que geralmente são de negação, resignação, revolta, confusão e culpa, geram consequentemente choque e tristeza (Silva \& Ramos, 2014) e quando isso ocorre, inicia-se uma crise na família. Esta reação pode ser compreendida como normal, visto que diante da notícia, a família precisa reajustar seus planos e expectativas frente à nova realidade. Na sociedade brasileira, é comum que os indivíduos não sejam estimulados a pensar naquilo que foge aos padrões de normalidade. Assim, o sentimento de crise diante do evento traumático toma uma proporção grandiosa, que faz com que o grupo familiar precise desconstruir tais crenças e pensamentos a fim de recriar uma nova gama de conceitos que envolva a realidade. (Glat, 1996; Batista \& França, 2007).

Nesse processo existe a confrontação de três filhos, em que segundo Lebovici (1992), o primeiro é o filho da fantasia, derivado do desejo inconsciente da maternidade, que não inicia na decisão da mulher por ter um bebê, mas sim em uma construção proveniente já na infância. (Stenr, 1977; Lebovici, 1992; Winnicott, 2008). Em seguida, o filho imaginário surge no ideário pré-consciente da mãe durante a gestação, e nesse momento, a mãe começa a imaginar como será a aparência do bebê. A partir do terceiro trimestre de gestação, a preocupação da mãe gira em torno da saúde do bebê, com anseio de que este seja perfeito. Quando o bebê nasce, existe então um confronto entre a dupla referência dos registros inconscientes e pré-conscientes. É neste momento que a representação do bebê idealizado 
dá lugar ao bebê real (Lebovici, 1992) e, a partir disso, começa a estabelecer-se o vínculo entre mãe e bebê.

No desenvolvimento do bebê com deficiência, torna-se importante que a mãe e a família o aceitem com suas limitações, visto que o vínculo mãe-bebê, desde o período perinatal, contribui na formação do alicerce da personalidade da criança, isto é, seu desenvolvimento emocional. A partir disso, a criança constroi sua capacidade para tolerar a frustração, pois desde muito cedo o bebê deseja de sua mãe amor e compreensão. (Klein, 1991; Winnicott, 2008).

Existem fases pelas quais as famílias passam desde a descoberta da deficiência até a aceitação. A primeira fase refere-se à negação, em que ocorre um choque frente ao inesperado e suscita dúvidas quanto ao futuro imprevisível. (Batista \& França, 2007). Após a fase de luto pelo bebê ideal, os pais entram em um processo de adaptação. Encontram-se então, em um misto de tristeza, raiva e revolta: é o momento do isolamento, em que são colocadas à prova suas capacidades e habilidades para cuidar do bebê com deficiência. (Sá \& Rabinovich, 2006). Tratando desta fase, Batista e França (2007) enfatizam que a família empenha-se em descobrir formas de adequar-se ao novo momento existencial. Isso ocorre na busca de maiores informações sobre o diagnóstico, agora não para negar a deficiência, mas para melhor compreendê-la. Uma vez diante do problema, a família desenvolve mecanismos próprios para enfrentá-lo, que variam de acordo com as crenças culturais e com recursos sócio-sanitários. (Sá \& Rabinovich, 2006). A próxima etapa vivenciada pela família é a fase de aceitação, na qual o contato maior com o que antes era novidade possibilita uma visão mais realista, tanto da criança como de sua deficiência, e o vínculo emocional já está devidamente estabelecido. A evolução da criança é percebida gradativamente e os pais já se tornam mais participativos, buscam cada vez mais apoio, sugestões e esclarecimentos. Diante desse quadro, alguns pais reconhecem que tristeza e frustração são sentimentos que devem ser encarados com naturalidade, e assim, estabelecem novos parâmetros de comparação e expressam satisfação frente às conquistas do filho. (Batista \& França, 2007).

As fases e os sentimentos pelos quais os pais passam, interferem no acolhimento da criança e pode haver um comprometimento no vínculo afetivo pais-criança. Quando os pais perdem o filho desejado e não elaboram o luto, se encontram impedidos de vincularem-se ao bebê real. (Sá \& Rabinovich, 2006; Silva \& Ramos, 2014). Assim, podem ficar melancólicos ou estabelecer um vínculo com a deficiência e não com o filho, tornando-se mártires ou vítimas de um castigo, sentindo-se culpados frequentemente. (Sá \& Rabinovich, 2006). Dito isto, compreende-se que o acompanhamento psicológico ou a participação em grupos de apoio tornam-se estratégias necessárias para que a família consiga passar pelas fases descritas anteriormente, de modo a elaborar o luto e proporcionar um desenvolvimento adequado ao bebê.

\section{Caracterização do serviço de estimulação precoce}

De acordo com documentos brasileiros, admite-se que a prevenção em EP ocorre, além de em uma abordagem multissetorial, na viabilização e promoção da participação familiar no processo. (MEC, 1995a; 1995b). Para que a criança evolua, a família tem um papel fundamental e deve receber apoio e orientação dos profissionais envolvidos para possibilitar a continuidade do trabalho no lar. A EP consiste no atendimento, desde o nascimento, à criança de alto risco, ou seja, aquela que apresenta problemas evolutivos originários de fatores ambientais ou orgânicos. Através de técnicas aplicadas por equipes multiprofissionais, a EP viabiliza condições para que a criança alcance seu desenvolvimento pleno por meio de experiências e vivências significativas decorrentes do contato com as pessoas, objetos e espaços por meio da estimulação sensório-perceptiva, motora, cognitiva, de comunicação e de aquisição de hábitos da vida diária, com o intuito de que a criança atinja padrões de desenvolvimento adaptáveis às suas características e possibilidades. Além disso, a EP contempla objetivos relacionados às mudanças de comportamento das pessoas do convívio da criança, sobretudo aquelas que se encarregam da função de mediadoras no processo, ou seja, seus pais, familiares e educadores. (MEC, 1995a; 1995b; Ministério da Saúde [MS], 2016).

Nesse cenário, contrário às práticas utilizadas na década de 70, em que o atendimento preocupava-se essencialmente com a criança, como apontam Hansel e Bolsanello (2012), e por consequência das mudanças sobre a participação ativa dos pais nos atendimentos, percebe-se atualmente a necessidade de ampliar os esforços da intervenção para o contexto no qual a família está inserida, isto é, a comunidade. Em vista disso, a área da EP tem evoluído significativamente nos últimos anos ao sair de uma perspectiva centralizada na criança e adentrar a uma perspectiva que contempla a família e os diferentes contextos de desenvolvimento como um novo modo de atuação. Tal mudança tem gerado progressos significativos nos atendimentos a partir da inclusão de um trabalho mais dinâmico em EP, reconhecendo a importância das interações humanas e experiências familiares em benefício tanto da criança quanto de seus familiares. (Hansel \& Bolsanello, 2012).

\section{Método}

Para alcançar os objetivos desta pesquisa, optou-se pela realização de um estudo de casos múltiplos, de caráter qualitativo.

Participaram do estudo 3 mães e um pai de crianças em atendimento no serviço de EP, totalizando 4 participantes e 3 famílias. Para a entrevista, optou-se pelo principal cuidador, contudo, promoveu-se a participação de mais de um, caso houvesse interesse. Desse modo, em uma das famílias, ambos os pais participaram da entrevista.

A coleta de dados ocorreu mediante a realização de entrevistas semiestruturadas. Para isto, elaborou-se o Termo de Consentimento Livre e Esclarecido, que foi apresentado aos participantes anteriormente ao início das entrevistas. A medida utilizada consistiu de gravação das entrevistas, que posteriormente foram transcritas e analisadas.

As análises das entrevistas foram estruturadas em três etapas, como sugere Bardin (1977) para a Análise de 
Conteúdo. A primeira consistiu na categorização dos dados a partir de temáticas expressas nos discursos dos entrevistados. Após a categorização, realizou-se a codificação dos dados, que consiste na exploração do material a fim de organizar as informações. Para finalizar, fez-se a interpretação dos dados, "tratados de maneira a serem significativos e válidos.” (p. 101).

\section{Discussão dos resultados}

As crianças cujas famílias participaram das entrevistas, iniciaram os atendimentos na instituição entre o período de 2015 a 2017, com idade variando entre dois a três anos. Para manter em sigilo as identidades dos participantes, optou-se pela substituição de seus nomes verdadeiros da seguinte forma: M1 e P1, pais de A, diagnosticada com Síndrome de Down; M2, mãe de B, portadora de uma deficiência rara e M3, mãe de C, diagnosticada com Síndrome de Cornélia de Lange. Como exposto anteriormente, o estudo investigou as concepções dos familiares de crianças que participam do serviço de EP acerca de sentimentos originados na descoberta da deficiência, bem como sobre os benefícios do programa. Isto posto, os resultados compreendem as seguintes categorias:

\section{Sentimentos envolvidos na descoberta da deficiência}

Os sentimentos de ansiedade e medo em relação a ter um filho com deficiência iniciam, geralmente, durante a gestação, como o caso de M1, ou no parto, como referido por M3. Por vezes, o diagnóstico não é realizado no momento do nascimento, como relata M1. Esta observou o bebê durante alguns dias até perceber que apresentava alguns sinais que poderiam fazer parte do quadro da Síndrome de Down. Assim sendo, foram realizados alguns exames e a síndrome foi constatada. Nas palavras de M1: "Até o último momento a gente esperava que ela não tivesse. Eu realmente, eu fiquei... a gente fica chocado [...] O pai ficou meio chocado, meio frustrado [...] Foi uma frustração quando a gente descobriu". Esta fala apresenta um dos momentos descritos por Lebovici (1992), como o luto do filho real, visto que antes mesmo da gestação a mãe já tem representações e expectativas acerca de como será seu filho. "A gente não quer [uma deficiência], a gente quer o melhor” (M1), nota-se aqui, a idealização de um filho saudável e perfeito. Tais representações são confrontadas no nascimento do bebê, como relata M3: "Eu fiquei nervosa porque eu fiz todo o pré-natal e eu não soube nem da má formação dela, então pra mim foi uma surpresa". Nesse momento, instala-se na família um sentimento de crise, salientado pela falta de informação sobre a deficiência, como relata M1: “A gente não tem informação de como é e de como vai ser, porque cada um desenvolve de um jeito. O que ela vai ter, o que ela não vai, o que ela vai poder, o que não vai.”.

O sentimento de medo é constatado na fala do pai: "Tu fica com aquele medo, 'será que pode caminhar, será que não vai falar?"” (P1). Assim como M1, M2 demonstra que o momento da descoberta foi complicado, "Na hora foi um choque", ressaltando ainda as limitações características da deficiência: "Ela não ia caminhar ainda, no ponto de sentar, no ponto de comer" (M2). Nessa perspectiva, M3 diz: "Bateu um desespero porque nós pensávamos que poderia ser só uma má formação, e depois vieram as outras características do retardo mental". Percebe-se que para os pais, o momento da descoberta caracterizou-se como um choque, descrito por Batista e França (2007) como parte de um período de negação frente ao inesperado, que suscita dúvidas quanto a um futuro imprevisível. Notou-se nas entrevistas que a incerteza pode ser extremamente ansiogênica para os pais, como demonstrado no discurso de M3, ao mencionar ter ficado muito nervosa com a dimensão dos prejuízos que a filha poderia ter. Em vista disso, enfatizamos que o apoio social e profissional pode auxiliar neste momento.

De acordo com o relato de M1, o esposo a chamava de louca quando esta começou a perceber características da Síndrome de Down na filha. Quando o diagnóstico se concretizou, ele se isolou e não conversou sobre seus sentimentos em relação à situação. Nesse sentido, inferimos que a experiência em participar da pesquisa pode ter contribuído para a representação dos sentimentos desencadeados pela descoberta da deficiência e de experiências vivenciadas pelo pai, pois a partir do momento em que a família conscientiza-se e inicia o tratamento, muitos desses sentimentos iniciais se dissolvem. Em vista disso, M2 relata que as fisioterapeutas lhe ensinaram algumas atividades para fazer com sua filha em casa, mas que esse é um momento difícil, pois a filha chora bastante. Nota-se que M2 tem consciência de que a filha tem uma síndrome rara, mas apesar disso, é capaz de reconhecer as limitações e potencialidades da mesma. A mãe busca conhecimentos acerca desses processos. "Eu gosto de estar pertinho para ver, eu aprendo [...] É uma troca, não é só ela aprende, eu aprendo muita coisa com ela também" (M2). Essa lógica de pensamento assemelha-se ao que elucidam Batista e França (2007) sobre a fase de adaptação, momento em que a família empenha-se em descobrir formas de adequar-se ao novo contexto, por meio da busca por maiores informações sobre o diagnóstico a fim de compreendê-lo.

O que caracteriza a fase de aceitação é uma visão mais realista, tanto da criança como de sua deficiência, o que possibilita observar que a evolução da criança ocorre gradativamente. (Batista \& França, 2007). Tal concepção é expressa no discurso de M1: "Ela é uma criança normal da idade dela, eu acho. Eu vejo ela assim, não vejo a síndrome [...] No meu ponto de vista, como mãe a A. está se desenvolvendo super bem". Indo ao encontro deste trecho, M2 diz: "Eu nem vejo que ela tem problema. $\mathrm{Na}$ verdade, apesar de eu saber que ela tem muitos problemas, eu vejo ela como uma criança normal". Observando essa mudança na visão dos pais em relação aos filhos, M3 enfatiza que sua filha "tem esse atraso, eu vejo que é diferente das outras crianças", entretanto refere que atualmente, "já vejo que ela é mais ativa pra essas atividades". Na fase de aceitação, os pais já se tornam mais participativos e buscam cada vez mais apoio e sugestões. Nesse sentido, M2 destaca que participa de um grupo de apoio a mães de filhos com necessidades especiais: "Parece que a gente fica leve, tu vê todo mundo junto, enfrentando os mesmos problemas". Outra 
mãe diz: "Eu participo só de grupos de mães da síndrome dela, mas tudo via rede social.” (M3).

Um elemento que merece ser destacado é a integração da criança com deficiência na família, pois de acordo com Glat (1996), o papel da família é fundamental nesse processo. Esse pressuposto é exemplificado na fala de M1: "A estimulação maior é ser tratada igual. Ela é igual os outros filhos, a gente exige dela, dentro das condições dela, dentro do que ela pode oferecer, tudo como a gente exige dos outros. Ela é normal.".

A partir do exposto até aqui, percebe-se que desde a descoberta da deficiência, até o período de aceitação, torna-se necessário, por parte dos pais, um grande empenho que perpassa sentimentos desde a frustração até a compreensão da deficiência, possibilitando aos membros da família rever antigos preconceitos. Nesse contexto, a família é essencial, tanto para a eficácia do tratamento quanto para a integração do filho com deficiência na sociedade.

\section{Concepções dos pais acerca da estimulação precoce}

Como dito anteriormente, os modelos de intervenção vêm evoluindo para modelos centrados na família. Nesse sentido, a intervenção dos profissionais será mais significativa se estes notarem que a criança está inserida em um contexto familiar em que o desenvolvimento é estimulado. Em um estudo sobre a abordagem centrada na família, Graça, Teixeira, Lopes, Serrano e Campos (2010) inferem que nessa abordagem é oferecido à criança e sua família um contexto mais natural, em que é oportunizado o envolvimento dos pais e observa-se o comportamento da criança em atividades significativas para esta. Desse modo, valoriza-se a participação e a inclusão dos pais como membros da equipe.

Sobre a participação nos atendimentos de EP, as mães M2 e M3 relatam que participam de modo a observar o processo e prestar auxílio quando necessário. Segundo M3: "Eu observo e quando elas [estimuladoras] precisam de ajuda para alguma coisa, quando ela chora ou alguma coisa assim, ou ela tá ficando mais enjoadinha porque ela cansa, eu tento entreter para as gurias conseguirem seguir o atendimento.". Já M1 conta que participou algumas vezes no início, mas que por conta do comportamento da filha, a estimuladora sugeriu que não participasse para que o trabalho fosse mais eficaz: "No início eu fiquei uma aula ou duas. Ela fazia fisioterapia e fazia estimulação [...] Mas daí a professora achou melhor que eu esperasse para ela se desenvolver melhor. A minha presença ali poderia deixar ela tímida e deu certo.” (M1).

Além disso, os pais relatam sobre as atividades que desenvolvem com as crianças em casa, seguindo as orientações e observações de procedimentos realizados pelos profissionais na instituição. Sobre isso, a mãe M1 afirma: "A gente tenta auxiliar e eu acho que está dando certo. Ela tem se desenvolvido bem para a idade dela.", por outro lado, M2 encontra alguma dificuldade nas atividades de casa, pois segundo ela, sua filha chora sempre. Nas palavras da mãe: "Elas [estimuladoras] me explicam o que elas fazem com ela e eu faço, geralmente à noite [...] Chorando todo tempo, porque ela detesta". Na perspectiva do pai, tanto o atendimento na instituição, quanto as atividades realizadas em casa trouxeram muitos benefícios para a filha e também à família, como expõe na seguinte fala: "Hoje eu participo bastante das atividades com a A, foi onde eu pude ver bastante coisa, foi onde eu aprendi muito." (P1).

A mãe M1 apresenta o déficit na fala como principal limitação de sua filha. Em vista disso, Mayer, Almeida e Lopes-Herrera (2013) enfatizam que a comunicação requer "habilidades básicas, como a capacidade para iniciar, interagir, responder apropriadamente ao que está sendo questionado, além de manter a interação." (p. 344). Conforme informa $\mathrm{M} 1$, a respeito da comunicação com a filha, "Ela pode até não falar, mas ela se expressa, a gente se entende e ela entende tudo o que eu falo." (M1). Em vista disso, o MS (2016) destaca que a necessidade de comunicação entre os seres humanos faz com que as pessoas se apropriem da linguagem e, através desta, passam "a nomear o mundo, organizar suas experiências, construir e expressar ideias ou opiniões.” (p.68). Dessa forma, o desenvolvimento da comunicação, linguagem e cognição baseia-se na percepção, na fala e no afeto. $\mathrm{Na}$ criança com déficit neurológico, a estimulação da comunicação procura ampliar suas possibilidades de expressão, seja pela fala, por gestos ou expressões faciais. (MS, 2016). A mãe M1 destaca ainda, que tem percebido melhora desde que a filha iniciou a estimulação: “Quando ela chegou só dizia 'não', era tudo 'não'. Agora ela já está no 'sim', já consegue falar mais algumas palavrinhas. Então é muito importante, não só para o desenvolvimento físico, mas para ela estar interagindo." (M1).

As mães M2 e M3 apontam para as dificuldades psicomotoras das filhas como fatores principais de suas limitações, segundo M2: "Ela nem se mexia, parecia uma bonequinha.". M3, por sua vez, conta que "Além da má formação, ela tem a parte do retardo mental. Ela pode ter o atraso na fala, o atraso psicomotor [...] Ela tem um atraso normal, porque talvez uma criança com dois anos já estaria caminhando, mas ela não" (M3). Nesse contexto, em uma revisão sobre o desenvolvimento motor infantil, enfatiza-se que a identificação e a intervenção em desvios do desenvolvimento motor são essenciais para o prognóstico de crianças com algum distúrbio no desenvolvimento. Nos primeiros anos de vida, as intervenções auxiliam no desenvolvimento e previnem possíveis incapacidades. (Willrich, Azevedo \& Fernandes, 2008).

Quando interrogados sobre a evolução dos filhos desde o início dos atendimentos na instituição, todos os pais afirmam que são muitos os benefícios e que percebem uma melhora significativa no desenvolvimento das crianças. A mãe M1 afirma: "Serve muito pra organizar os pensamentos dela. Ela já consegue sentar, brincar sentada, escrever. Ela gosta de pintar, desenhar". Para o pai, a partir da interação com a filha, "foi uma escola porque eu pude acabar com os meus preconceitos, aprender um pouco mais sobre as necessidades deles, o tempo deles". (P1). A respeito do preconceito, Goés (2006) sustenta que a subjetividade é construída na e pela cultura, portanto os pais são influenciados pelo ambiente cultural e junto de suas experiências de vida, constroem valores geralmente negativos sobre a deficiência, pois as representações sociais expressam, 
ainda hoje, qualidades desfavoráveis sobre as pessoas com deficiência.

Referente às limitações do desenvolvimento motor das filhas, M2 e M3 reconhecem que a entrada delas na instituição surtiu efeitos positivos. Nas palavras de M2: "Agora ela está querendo pegar os brinquedos, já está brincando [...] Não faz muitas coisas ainda, mas está mais firmezinha na parte de sentar. Está sendo muito importante pra ela sentar, caminhar, pra tudo". Nessa perspectiva, M3 refere: "Pra mim, pelo pouco tempo que ela está aqui, já vejo bastante diferença nela, no comportamento dela, principalmente a parte de fisioterapia. Ela já consegue sentar, ela já consegue ficar mais estabilizada em pé", acrescentando ainda, que diante de outros estímulos a filha também tem evoluído: "Ela está mais ativa para os sons, para os brinquedos, para todas as atividades ela já fica um pouco mais alerta. Eu vejo que ela está dando um salto no desenvolvimento." (M3).

Em vista dos relatos expostos nesta sessão, nota-se que todos os pais concordam quanto aos atendimentos de EP terem benefícios para o desenvolvimento de seus filhos. Concernente à participação das famílias no processo de EP, observou-se que essa possui caráter assistencial, tendo em vista que ocorre quando as especificidades da criança exigem um cuidado complementar.

\section{Considerações finais}

A partir das análises, compreendemos que desde o momento da descoberta da deficiência até o início do tratamento em EP, muitos sentimentos permeiam o âmbito familiar. Desse modo, inferimos que participar da pesquisa pode ter contribuído para a representação de sentimentos oriundos desse momento, visto que a aceitação da família contribui de muitas formas para o tratamento dos filhos. Em vista disso, entendemos que as famílias têm consciência de que a EP visa favorecer condições pelas quais a criança possa se desenvolver integralmente, percebendo sua importância e benefícios, bem como participando quando há a necessidade.

\section{Referências}

Bardin, L. (1977). Análise de conteúdo. (70a ed.). Lisboa Batista, S. \& França, R. (2007). Família de pessoas com deficiência: desafios e superação. Revista de divulgação técnico-científica do ICPG, 10(3), 117-121.

Glat, R. (1996). O papel da família na integração do portador de deficiência. Revista Brasileira de Educação Especial, 1(4), 111-118. http://www.abpee.net/homepageabpee04_06/artigos_e m_pdf/revista4numero1pdf/r4_art09.pdf

Graça, P., Teixeira, M., Lopes, S., Serrano, A. \& Campos, A. (2010). O momento da avaliação na intervenção precoce: o envolvimento da família estudo das qualidades psicométricas do ASQ-2 dos 30 aos 60 meses.Revista Brasileira de Educação Especial, 2(16), 177-196.https://dx.doi.org/10.1590/S1413-653820100 00200003

Goés, F. A. (2006). Um encontro inesperado: os pais e seu filho com deficiência mental. Psicologia: ciência e profissão,

$3(26)$,

450-461.

http://pepsic.bvsalud.org/scielo.php?script=sci_arttext \&pid=S1414-98932006000300009\&lng=pt\&tlng=pt

Hansel, A. F. (2012). Estimulação precoce baseada em equipe interdisciplinar e participação familiar: concepções de profissionais e pais (Tese de doutorado). Programa de Pós-Graduação em Educação, Universidade Federal do Paraná, Curitiba, Brasil. http://hdl.handle.net/1884/35387

Hansel, A. F. \& Bolsanello, M. A. (2012, julho). As abordagens explicativas do desenvolvimento aplicadas à estimulação precoce. Anais do Seminário de Pesquisa em Educação da Região Sul.Caxias do Sul, 9. http://www.portalanpedsul.com.br/admin/uploads/201 2/Educacao_Especial/Trabalho/08_28_14_2632-7319 -1-PB.pdf

Klein, M. (1991). Inveja e Gratidão e outros trabalhos (1946-1963). Rio de Janeiro: Imago.

Lebovici, S. (1992). Maternidade. In Costa, G. P.; Katz, G. (Org.). Dinâmica das relações conjugais. (pp. 41-61). Porto Alegre: Artes Médicas.

Mayer, M. G., Almeida, M. A. \& Lopes-Herrera, S. A. (2013). Síndrome de Down versus alteração de linguagem: interação comunicativa entre pais e filhos. Revista Brasileira de Educação Especial, 3(19),343-362. http://dx.doi.org/10.1590/S1 413-65382013000300004

Ministério da Educação. (1995a). Diretrizes educacionais sobre estimulação precoce: o portador de necessidades educativas especiais. MEC, Brasília.

Ministério da Educação. (1995b). Subsídios para organização e funcionamento de serviços de educação especial: área de deficiência mental. MEC, Brasília.

Ministério da Saúde. (2016). Diretrizes de estimulação precoce: crianças de zero a 3 anos com atraso no desenvolvimento neuropsicomotor. MS. Brasília.

Minuchin, S. (1982). Um modelo familiar. In Minuchin, S. Famílias: funcionamento e tratamento. (pp. 52-69). Porto Alegre: Artes Médicas.

Pichon-Rivière, E. (1998). O processo grupal. São Paulo: Martins Fontes.

Sá, S. M. \& Rabinovich, E. P. (2006). Compreendendo a família da criança com deficiência física. Journal of Human Growth and Development. 1(16), 68-84. http://pepsic.bvsalud.org/scielo.php?script=sci_arttext \&pid=S0104-12822006000100008\&lng=pt\&tlng=pt

Silva, C. \& Ramos, L. (2014). Reações dos familiares frente à descoberta da deficiência dos filhos. Cad. Terapia Ocupacional. 1(22), 15-23. http://doi.editoracubo.com.br/10.4322/cto.2014.003

Stern, D. N. (1997). A constelação da maternidade: o panorama da psicoterapia pais/bebê. Porto Alegre: Artes Médicas.

Willrich, A., Azevedo, C. \& Fernandes, J. O. (2008). Desenvolvimento motor na infância: influência dos fatores de risco e programas de intervenção. Revista Neurociências, in press, 1-6. http://services.epm.br/dneuro/neurociencias/226_revis ao.pdf

Winnicott, D. W. (2008). A criança e o seu mundo. Rio de Janeiro: LTC. 